Geraldo BALIEIRO NETO ${ }^{1}$ Laércio MELLOTI ${ }^{2}$

Correspondência para: Av. Bandeirantes 2419, Bairro Vila Virginia, Ribeirão Preto, SP, CEP 14030-670

geraldobalieiro@aptaregional.sp.gov.br Trabalho financiado pela FAPESP

Recebido para publicação: 03/02/2006 Aprovado para publicação: 24/05/2007

\title{
Efeitos de níveis de sebo sobre a degradabilidade in situ do farelo de soja e do feno de tifton \{Cynodon dactylon (L.) pers.\} em vacas secas
}

\author{
1. Pesquisador Científico da Agência Paulista de Tecnologia dos Agronegócios - \\ APTA Regional Centro-Leste \\ 2. Professor aposentado da Faculdade de Medicina Veterinária e Zootecnia da \\ Universidade de São Paulo, São Paulo -SP
}

\section{Resumo}

Os efeitos da suplementação com sebo foram estudados em experimento delineado em dois Quadrados Latinos 3 x 3, utilizandose seis fêmeas bovinas dotadas de cânulas ruminais. Os tratamentos foram três, dieta controle (sem suplementação de sebo), dieta com $3 \%$ ou dieta com $6 \%$ de sebo na matéria seca total, todas com $60 \%$ de volumoso. O experimento teve três períodos de 28 dias, sendo os 21 primeiros destinados à adaptação dos animais a dieta, composta de feno de Tifton (Cynodon dactylon) e mistura de concentrados. O ensaio de degradabilidade in situ foi realizado do $21^{\circ}$ ao $28^{\circ}$ dia. Os tempos de incubação foram 6; 12; 24; $48 ; 72$ e 96 horas para MS e FDN do feno de Tifton e 1,5; 3; 6; 12; 24 e 48 para MS e PB para o farelo de soja. O tempo zero foi usado para avaliar a fração solúvel. Observou-se redução da degradabilidade efetiva da MS e FDN do feno de Tifton e aumento da degradabilidade efetiva da MS e PB do farelo de soja com o aumento de sebo na dieta.

\section{Introdução}

A suplementação de lipídios pode contribuir para o fornecimento de níveis de energia mais próximos aos requerimentos dos animais de alta produção, proporcionar balanço mais adequado entre carboidratos estruturais e não estruturais da ração, otimizar a utilização de energia digestível ${ }^{1}$ e minimizar problemas de estresse calórico comum em altas produtoras em regiões tropicais ${ }^{2,3}$.

No entanto, altas concentrações de ácidos graxos exercem efeito marcante na ecologia e no metabolismo do rúmen. Os mecanismos através dos quais os ácidos graxos afetam a fermentação ruminal envolvem a adsorção às bactérias e partículas alimentares e toxicidade ${ }^{4,5}$. A aderência às bactérias pode prejudicar a tomada de nutrientes, e o revestimento das partículas alimentares pode diminuir a digestibilidade. Já a toxicidade, deve-se a habilidade dos ácidos graxos em romper a membrana celular microbiana, prejudicando a função celular e atividade das enzimas hidrolíticas bacterianas. Trabalhos publicados demonstram que o efeito da gordura sobre a degradação ruminal difere entre as fontes e níveis de suplementação utilizados ${ }^{6}$. Estudos in vitro e in vivo demonstraram que gorduras com alto ponto de fusão, como o sebo, são "inertes" no rúmen, sendo pouco provável a sua adsorção às bactérias ou partículas alimentares $^{7}$. Entretanto os efeitos da suplementação de lipídios tem sido bastante variáveis, fenômeno que pode ser explicado pela complexidade dos fatores que interferem nas respostas.

\section{Material e Método}

O trabalho foi conduzido nas instalações do Departamento de Nutrição e Produção Animal da Faculdade de Medicina 
Veterinária e Zootecnia no Campus Administrativo de Pirassununga - FMVZ / USP. Foi utilizado um delineamento experimental em dois Quadrados Latinos 3 x $3{ }^{8}$ com dois grupos de três animais cada em três subperíodos experimentais de 28 dias de duração, para testar três tratamentos com diferentes níveis de sebo na dieta total, A) $0 \%$, B) 3\% ou C) $6 \%$. Foram utilizadas seis fêmeas bovinas mestiças, Holandês x Zebu com graus de sangue variáveis, portadoras de fistula ruminal "Bar Diamond" com 10 $\mathrm{cm}$ de diâmetro e $7,5 \mathrm{~cm}$ de expessura. Os animais possuiam aproximadamente três anos e meio de idade e $480 \mathrm{~kg}$ de peso vivo, em média, ao início do experimento. Apresentavam-se não lactantes e não gestantes, sendo dois animais nulíparos e quatro primíparos.

As três dietas foram formuladas para serem isoprotéicas, sendo o concentrado constituído de grãos de milho moído, farelo de soja, premix mineral e sebo nos tratamentos B e C. O único volumoso utilizado foi o feno de Tifton (Cynodon dactylon) em proporções volumoso: concentrados de 60:40. Amostras de feno e das misturas concentradas foram realizadas diariamente durante a terceira semana de cada período experimental sendo homogeneizadas, ao longo de todo o experimento. As composições das dietas encontram-se na tabela 1.

O experimento teve duração total de 84 dias divididos em três períodos de 28 dias cada, sendo que os primeiros 21 , dentro de cada período, foram destinados para que os animais se adaptassem à dieta, e para que fosse feito um ajuste da ingestão de alimentos. O período compreendido entre o $21^{\circ}$ ao 28 dia foi utilizado para a avaliação da degradabilidade in situ. O consumo de alimentos foi à vontade e a proporção entre volumoso e concentrado não foi alterada. Os animais foram alimentados quatro vezes ao dia às 8:00; 13:00; 17:00; e 22:00 horas e pesados no início e final de cada período.

A degradabilidade in situ da MS e PB do farelo de soja e da MS e FDN do feno de Tifton foi medida através da técnica de sacos de náilon in situ conforme descrito por Orskov, Hovell e Mould ${ }^{9}$. Para tal, utilizaramse sacos medindo $10,0 \times 19,0 \mathrm{~cm}$ previamente identificados e pesados em balança analítica de precisão (marca Marte, modelo 200). Posteriormente, receberam aproximadamente 7 g da amostra de farelo de soja e aproximadamente $6 \mathrm{~g}$ da amostra do feno de Tifton previamente secos em estufa de ar forçado a $65^{\circ} \mathrm{C}$ por 72 horas, sendo o farelo de soja, obtido após incubação, previamente processado em moínho Wiley Mill com peneira de 20 mesh e o feno moído em peneira de $5 \mathrm{~mm}$. O farelo de soja possuía $52 \%$ de PB (base na MS) e o feno de Tifton $76 \%$ de FDN. Após serem amarrados, os saquinhos foram armazenados em câmara fria até o momento do uso. Durante a incubação, os sacos foram presos, por meio de argolas metálicas de aço inoxidável, a mosquetões que permitiam fixá-los à cânula ruminal através de um fio de náilon com comprimento mínimo de $50 \mathrm{~cm}$, permitindo sua livre movimentação no interior do rúmen. Os sacos foram incubados durante 0h, 1,5h, 3h, 6h, 12h, 24h e 48 horas para as amostras de farelo de soja e 0h, 6h, 12h, 24h, 48h, $72 \mathrm{~h}$ e 96 horas para as amostras de feno. Imediatamente após a retirada, nos tempos pré-determinados, os sacos foram lavados à mão e em água corrente até que o líquido de lavagem fluísse incolor, sendo então colocados em estufa a $65^{\circ} \mathrm{C}$ por 72 horas para posterior pesagem e análises bromatológicas. A degradabilidade em tempo zero foi tomada mergulhando-se os sacos em um recipiente contendo água à temperatura de $39^{\circ} \mathrm{C}$ durante 10 minutos ${ }^{10}$.

As análises bromatológicas de $\mathrm{PB}$ foram avaliadas segundo A.O.A.C. ${ }^{11}$ e de FDN e FDA segundo Goering e Van Soest ${ }^{12}$.

Os dados de degradabilidade, calculados através da diferença de pesagens dos sacos antes e após a incubação, foram ajustados segundo a equação de Orskov e McDonald ${ }^{13}, p=a+b\left(1-e^{-t}\right)$, onde $\mathrm{p}$ é a quantidade degradada no tempo $(t), a$ representa a fração rapidamente solúvel, $b$ é a fração potencialmente degradável e $c$ a taxa de degradação na qual a fração descrita por 
Tabela 1 - Porcentagem de ingredientes utilizados nas dietas e composições bromatológicas, com base na MS. Pirassununga, SP, 1998

\begin{tabular}{|c|c|c|c|}
\hline \multirow[b]{2}{*}{ Ingredientes: } & \multicolumn{3}{|c|}{$\%$ dos Ingredientes nas rações } \\
\hline & Dieta A & Dieta B & Dieta C \\
\hline Feno & 60,0 & 60,0 & 60,0 \\
\hline Milho & 29,53 & 26,01 & 22,51 \\
\hline Farelo de Soja & 7,567 & 8,085 & 8,585 \\
\hline Sebo & 0,0 & 3,0 & 6,0 \\
\hline Calcário dolomitic & 2,2 & 2,2 & 2,2 \\
\hline Sal comum & 0,2 & 0,2 & 0,2 \\
\hline Sal Mineral & 0,5 & 0,5 & 0,5 \\
\hline Matéria seca & 86,58 & 86,76 & 87,13 \\
\hline$\% \mathrm{~PB}$ & 13,5 & 13,4 & 13,3 \\
\hline$\% \mathrm{EE}$ & 2,484 & 5,06 & 7,469 \\
\hline$\% \mathrm{FB}$ & 21,01 & 21,12 & 21,04 \\
\hline$\% \mathrm{FDN}$ & 49,52 & 49,28 & 49,04 \\
\hline$\%$ FDA & 26,84 & 26,78 & 26,73 \\
\hline$\% \mathrm{MM}$ & 6,968 & 7,038 & 6,795 \\
\hline$\%$ ENN & 56,03 & 53,38 & 51,40 \\
\hline$\% \mathrm{Ca}$ & 0,698 & 0,696 & 0,691 \\
\hline$\% \mathrm{P}$ & 0,242 & 0,260 & 0,250 \\
\hline $\mathrm{EM}(\mathrm{kcal} / \mathrm{kg})$ & $2.474,2$ & $2.557,0$ & $2.636,0$ \\
\hline
\end{tabular}

${ }^{1}$ Composição por kg de mistura mineral: $180 \mathrm{~g} \mathrm{Ca}, 90 \mathrm{~g} \mathrm{P}, 20 \mathrm{~g} \mathrm{Mg}, 20 \mathrm{~g} \mathrm{~S}, 100 \mathrm{~g} \mathrm{Na}, 155 \mathrm{~g} \mathrm{Cl}, 3.000 \mathrm{mg}$ Zn, $1.000 \mathrm{mg} \mathrm{Cu}$, $1.250 \mathrm{mg} \mathrm{Mn}, 2.000 \mathrm{mg} \mathrm{Fe}, 100 \mathrm{mg}$ Co, $90 \mathrm{mg}$ I, $20 \mathrm{mg} \mathrm{Se}, 900 \mathrm{mg}$ F (máximo).

$b$ será degradada por hora. As constantes $a$, $b$ e $c$ da equação exponencial foram utilizadas para calcular a degradabilidade potencial $(a$ $+b)$ e a degradabilidade efetiva $(D e)$ calculada através da seguinte fórmula:

$$
D e=a+(b \times c / c+k)
$$

onde $k$ representa a taxa de saída do rúmen por hora, sendo utilizadas taxas iguais a $0,02 / \mathrm{h}, 0,04 / \mathrm{h}$ e $0,06 / \mathrm{h}$, o que é justificado pelo fato de terem sido observados ganhos de peso médios de 710,850 e $625 \mathrm{~g}$ respectivamente para dietas com $0 \%, 3 \%$ e $6 \%$ de sebo.

Os parâmetros do modelo de regressão não linear pelo método de quadrados mínimos foram obtidos através do procedimento não linear (PROC NLIN) do programa computacional SAS ${ }^{14}$.

\section{Resultados e Discussão}

Foi observada uma redução da 
degradabilidade da MS do feno com efeito linear nos tempos de $12 \mathrm{~h}, 24 \mathrm{~h}$, e 72 horas (Tabela 2 e Figura 1) e redução linear da degradabilidade da FDN nos tempos de $12 \mathrm{~h}$, 24h, 48 h e 72 horas (Tabela 3 e Figura 2). Essa redução da degradabilidade demonstra os efeitos negativos dos ácidos graxos na fermentação ruminal. Os resultados presentes em dietas com $6 \%$ de sebo $(6,5 \%$ a mais de energia metabolizável) estão de acordo com trabalhos de Palmquist e Jenkins ${ }^{15}$ que sugerem tolerância até níveis de $4 \%$ a $5 \%$ a mais no total de energia disponível através da suplementação de lipídios, e também com Emanuelson, Murphy e Lindberg ${ }^{16}$ que encontraram menor degradabilidade ruminal da matéria orgânica e FDN para dietas com 5,8\% de sebo na MS da dieta e Zinn ${ }^{6}$ que ao avaliar o fornecimento de $5 \%$ de sebo observou redução da digestibilidade da $\mathrm{MO}$ e FDN em $6,9 \%$.

Os mecanismos através dos quais os ácidos graxos saturados de cadeia longa afetaram a degradabilidade da MS e FDN do feno não parecem ter envolvido efeitos de adsorção às bactérias e/ou partículas alimentares. Embora isso possa ter ocorrido, esse efeito é mais reconhecido na utilização de ácidos graxos de baixo ponto de fusão ${ }^{17} \mathrm{e}$ mesmo para estes não é certo de que este efeito de adsorção ocorra. Broudiscou, Van Nevel e Dmeyer ${ }^{18}$ observaram que a redução na degradabilidade foi semelhante cobrindo ou não a celulose com óleo de soja hidrolisado. Acrescido a isso, neste trabalho foi respeitado o teor mínimo de $21 \%$ de FDA $^{1}$ proporcionando competição entre fibras e bactérias na adsorção dos ácidos graxos, minimizando as possibilidades da ocorrência de adsorção.

A redução na degradabilidade da MS e FDN do feno parece ter ocorrido devido à redução de bactérias celulolíticas e de protozoários. Na dieta utilizada, com $60 \%$ de volumoso na MS total, não se observou fornecimento mínimo de $30 \%$ de amido como fonte de energia para crescimento microbiano ${ }^{2}$ e lipídios não fornecem energia para crescimento microbiano ${ }^{7,19,20}$. Além disso, o $\mathrm{pH}$ de 6,4 a 6,5 contribuiu para que houvesse alta atividade lipolítica aumentando a proporção de ácidos livres no meio, incluindo os ácidos graxos oléicos presentes no sebo e que podem ter sofrido pouca biohidrogenação nestes valores de $\mathrm{pH}^{21}$, tornando-se tóxicos as bactérias responsáveis pela degradação da fibra e protozoários, em especial para as bactérias gram-positivas (celulolíticas e metanogênicas) ${ }^{22}$. Houve efeito significativo linear sobre a contagem de protozoários ruminais $\left(202,170\right.$ e $60 \times 10^{8}$, respectivamente para 0,3 e $6 \%$ de sebo) que pode ter contribuido para a redução na degradabilidade da fibra. Mesmo com a defaunação, cabe mencionar que em níveis de $\mathrm{pH}$ superiores a $6,3 \mathrm{em}$ dietas com menores proporções de concentrado, além da lipólise ser favorecida, a atividade predatória dos protozoários para as bactérias é máxima ${ }^{23}$.

Segundo Weisbjerg, Borsting e Hvelplund $^{7}$ o efeito do fornecimento de sebo sobre a degradabilidade da fibra está relacionado ao nível de consumo, ocorrendo redução da degradação para baixos níveis de consumo. A ingestão de matéria seca de 8,5 a 9,4 kg/dia, observada neste trabalho, esteve muito próxima àquela considerada baixa no experimento de Weisbjerg, Borsting e Hvelplund $^{7}(8,6 \mathrm{~kg} / \mathrm{dia})$.

No trabalho de Weisbjerg, Borsting e Hvelplund $^{7}$ com a utilização de $0 \% ; 2 \% ; 4 \%$; e $6 \%$ de sebo adicionado à ração para vacas lactantes, houve ausência de efeito do aumento de sebo na digestibilidade da fibra no trato digestivo total. Embora saibamos do menor aproveitamento energético de alimentos volumosos no trato posterior, esses resultados mostram que dependendo da extensão em que é reduzida a degradabilidade ruminal da fibra, esta pode ser compensada pela maior digestão no intestino grosso ${ }^{7,24}$.

O efeito da suplementação do sebo sobre a degradabilidade da fibra mostra que o sebo não deve ser considerado fonte inerte no rúmen como cogitado por Chalupa e Ferguson $^{25}$. Embora pesquisadores como 
Tabela 2 - Efeitos de diferentes níveis de adição de sebo sobre a degradabilidade da MS do feno de tifton, em porcentagens, coeficientes de variação e probabilidades estatísticas. Pirassununga, SP, 1998

\begin{tabular}{|c|c|c|c|c|c|c|c|c|}
\hline \multirow{2}{*}{$\begin{array}{c}\underline{\text { MS }} \\
\text { Tempo(h) }\end{array}$} & \multicolumn{3}{|c|}{$\%$ de Gordura } & \multirow[t]{2}{*}{$\underline{\mathrm{CV}}$} & \multicolumn{2}{|c|}{ Probabilidade } & \multirow[t]{2}{*}{ Equacão 1} & \multirow[t]{2}{*}{$\underline{\mathbf{R}^{2}}$} \\
\hline & $\underline{\mathbf{0}}$ & $\underline{\mathbf{3}}$ & $\underline{6}$ & & $\underline{\mathbf{L}}$ & $\underline{\mathrm{DL}}$ & & \\
\hline 0 & $\overline{---}$ & 14,61 & $\overline{---}$ & $\overline{-\cdots---}$ & $\overline{---}$ & $\overline{---}$ & $-\cdots-$ & $\overline{---}$ \\
\hline 6 & 19,007 & 19,498 & 19,438 & 8,89 & 0,532 & 0,643 & --- & -- \\
\hline 12 & 32,413 & 33,936 & 29,475 & 8,63 & 0,024 & 0,011 & $\mathrm{D}=32,413+1,5 \% \mathrm{G}-0,332 \mathrm{G}^{2}$ & 0,477 \\
\hline 24 & 49,312 & 49,073 & 43,093 & 9,12 & 0,008 & 0,098 & $\mathrm{D}=50,27-1,036 \mathrm{G}$ & 0,369 \\
\hline 48 & 57,625 & 58,348 & 52,482 & 6,64 & 0,060 & 0,120 & --- & --- \\
\hline 72 & 61,293 & 61,038 & 57,190 & 5,43 & 0,044 & 0,262 & $\mathrm{D}=61,89-0,683 \mathrm{G}$ & 0,281 \\
\hline 96 & 64,333 & 62,695 & 62,182 & 2,56 & 0,057 & 0,414 & --- & --- \\
\hline
\end{tabular}

Parâmetros

\begin{tabular}{|c|c|c|c|c|c|c|c|c|}
\hline $\bar{a}$ & 11,826 & 11,913 & 12,775 & 7,943 & 0,058 & 0,328 & --- & -- \\
\hline b & 53,118 & 51,936 & 49,828 & 6,840 & 0,170 & 0,812 & --- & -- \\
\hline c & 0,041 & 0,045 & 0,039 & 22,3 & 0,316 & 0,620 & --- & -- \\
\hline Dp & 64,945 & 63,850 & 62,603 & 4,935 & 0,273 & 0,966 & --- & -- \\
\hline De 0,02 & 47,750 & 47,853 & 46,687 & 7,868 & 0,644 & 0,749 & ---- & --- \\
\hline 0,04 & 38,968 & 39,423 & 39,302 & 12,29 & 0,909 & 0,910 & --- & -- \\
\hline 0,06 & 33,637 & 34,204 & 34,914 & 15,60 & 0,695 & 0,979 & --- & -- \\
\hline
\end{tabular}

${ }^{1} \mathrm{D}=$ degradabilidade, $\% \mathrm{G}=$ porcentagem de sebo.

${ }^{2} a$, $b$ e $c$ referem-se aos parametros de Orskov e $\mathrm{McDonald}^{17}, \mathrm{Dp}=$ degradabilidade potencial, De $=$ degradabilidade efetiva para taxas de passagem iguais a 0,$02 ; 0,04$ e 0,06 .

${ }^{3}$ Números em negrito indicam que houve diferença estatisticamente significativa $(\mathrm{P}<0,05)$ para efeito linear $(\mathrm{L})$ ou desvio da linearidade (DL).

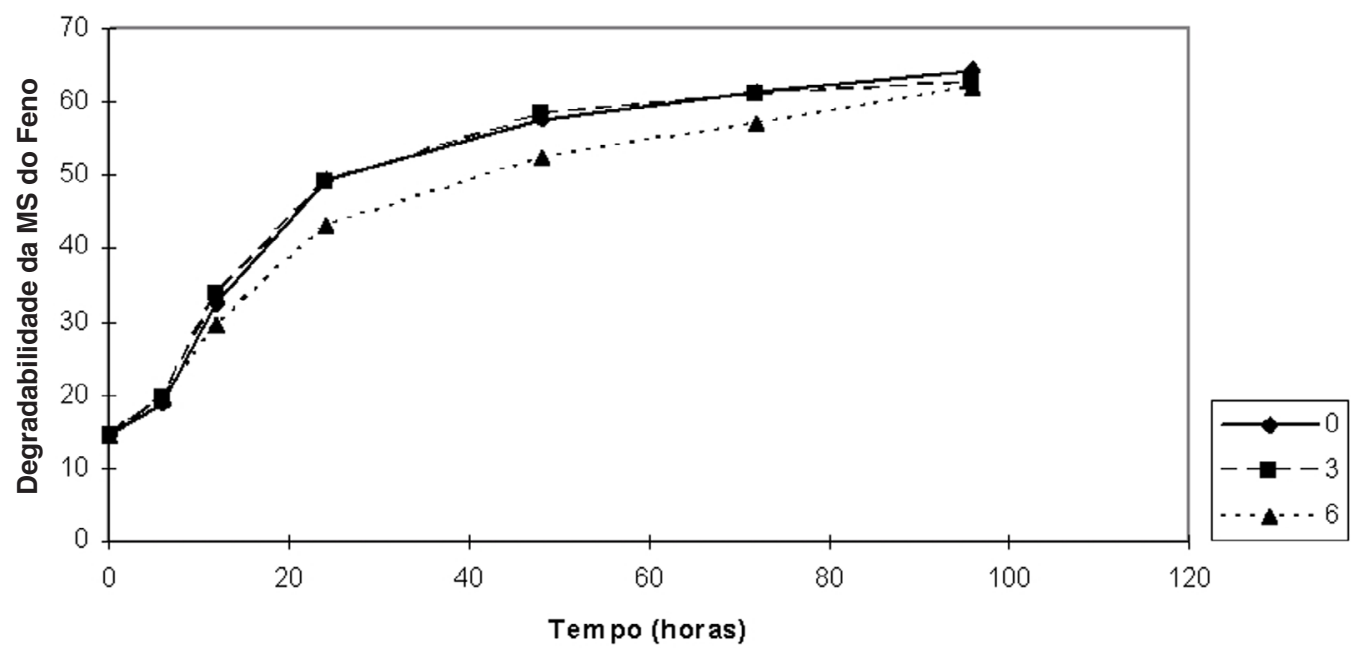

Figura 1 - Efeitos de diferentes níveis de adição de sebo (0, 3, 6\% da MS Total), em diversas horas de incubação, sobre a degradabilidade da MS do feno de Tifton 
Tabela 3 - Efeitos de diferentes níveis de adição de sebo na degradabilidade da FDN do feno, em porcentagens, coeficientes de variação e probabilidades estatísticas. Pirassununga, SP, 1998

\begin{tabular}{|c|c|c|c|c|c|c|c|c|}
\hline \multirow{2}{*}{$\begin{array}{c}\underline{\text { MS }} \\
\underline{\text { Tempo(h) }}\end{array}$} & \multicolumn{3}{|c|}{ \% de Gordura } & \multirow[t]{2}{*}{$\underline{\mathrm{CV}}$} & \multicolumn{2}{|c|}{ Probabilidade } & \multirow[t]{2}{*}{ Equacão $^{1}$} & \multirow[t]{2}{*}{$\underline{\mathbf{R}^{2}}$} \\
\hline & $\underline{0}$ & $\underline{3}$ & $\underline{6}$ & & $\underline{\mathbf{L}}$ & $\underline{\text { DL }}$ & & \\
\hline$\overline{0}$ & $\overline{c--}$ & 8,79 & $\overline{-\cdots}$ & 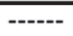 & $\overline{---}$ & $\overline{---}$ & $\overline{-\cdots--}$ & $\begin{array}{ll}--- \\
\end{array}$ \\
\hline 6 & 11,206 & 11,978 & 9,555 & 18,61 & 0,133 & 0,098 & ---- & $-\cdots$ \\
\hline 12 & 27,885 & 29,093 & 22,380 & 15,35 & 0,008 & 0,021 & $\mathrm{D}=27,88+1,723 \% \mathrm{G}-0,44 \mathrm{G}^{2}$ & 0,548 \\
\hline 24 & 46,122 & 45,877 & 38,508 & 12,03 & 0,007 & 0,091 & $\mathrm{D}=47,31-1,268 \% \mathrm{G}$ & 0,357 \\
\hline 48 & 55,347 & 55,690 & 49,067 & 7,93 & 0,044 & 0,140 & $\mathrm{D}=56,47-1,009 \% \mathrm{G}$ & 0,346 \\
\hline 72 & 59,012 & 58,597 & 54,297 & 6,61 & 0,048 & 0,301 & $\mathrm{D}=59,66-0,785 \% \mathrm{G}$ & 0,273 \\
\hline 96 & 61,602 & 60,537 & 59,664 & 2,91 & 0,338 & 0,749 & ---- & --- \\
\hline \multicolumn{9}{|l|}{ Parâmetros $^{2}$} \\
\hline a & 3,428 & 3,651 & 3,673 & 25,34 & 0,645 & 0,826 & ---- & $-\cdots$ \\
\hline b & 59,30 & 57,971 & 57,168 & 6,30 & 0,410 & 0,904 & ----- & ---- \\
\hline c & 0,045 & 0,046 & 0,034 & 20,06 & 0,003 & 0,020 & $\mathrm{D}=0,045+0,002 \% \mathrm{G}-0,0007 \% \mathrm{G}^{2}$ & 0,457 \\
\hline Dp & 62,728 & 61,623 & 60,841 & 5,435 & 0,419 & 0,934 & ---- & --- \\
\hline De 0,02 & 44,480 & 44,098 & 39,269 & 7,839 & 0,006 & 0,110 & $\mathrm{D}=45,22-0,868 \% \mathrm{G}$ & 0,429 \\
\hline 0,04 & 34,845 & 34,742 & 29,672 & 10,07 & 0,001 & 0,053 & $\mathrm{D}=35,672-0,862 \% \mathrm{G}$ & 0,424 \\
\hline 0,06 & 28,880 & 28,910 & 24,181 & 11,24 & 0,002 & 0,045 & $\mathrm{D}=28,88+0,803 \% \mathrm{G}-0,264 \% \mathrm{G}^{2}$ & 0,553 \\
\hline
\end{tabular}

$\mathrm{D}=$ degradabilidade, $\% \mathrm{G}=$ porcentagem de sebo, $\mathrm{NS}=$ não significativo.

${ }^{2} a$, $b$ e $c$ referem-se aos parametros de Orskov e McDonald ${ }^{13}, \mathrm{Dp}=$ degradabilidade potencial, De $=$ degradabilidade efetiva para taxas de passagem iguais a 0,$02 ; 0,04$ e 0,06 .

Números em negrito indicam que houve diferença estatisticamente significativa $(\mathrm{P}<0,05)$ para efeito linear $(\mathrm{L})$ ou desvio da linearidade (DL).

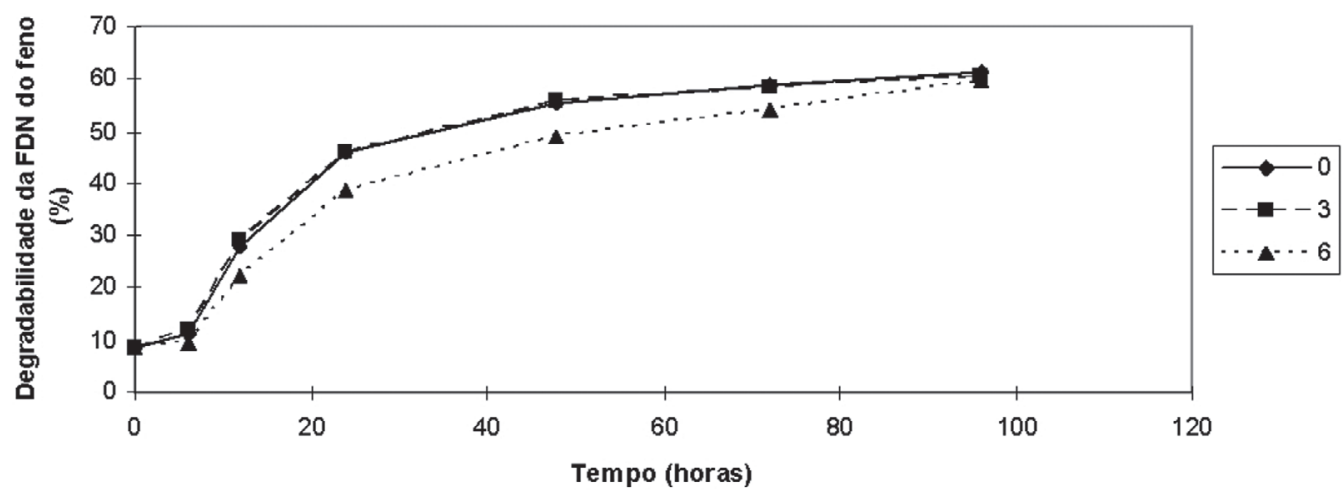

Figura 2 - Efeitos de diferentes níveis de adição de sebo (0, 3, 6\% da MS Total), em diversas horas de incubação,na degradabilidade da FDN do feno de Tifton 
Chalupa et al. ${ }^{26}$ e Weisbjerg e Borsting ${ }^{27}$ tenham mostrado menor efeito inibidor na degradabilidade da fibra do sebo comparado a ácidos graxos insaturados e ácidos graxos de cadeia média, o sebo também pode inibir a degradabilidade da fibra quando ofertado em níveis elevados e em valores de $\mathrm{pH}$ acima de 6,3, onde a atividade lipolítica é mais intensa. Por outro lado, Demeyer e Van $\mathrm{Neve}^{28}$ verificaram que a lipólise in vitro é inibida por valores de $\mathrm{pH}$ abaixo de 6,3, diminuindo ação do sebo na degradabilidade da fibra devido a efeitos tóxicos pela liberação dos ácidos graxos. Corroborando a este, Sukhija e Palmquist ${ }^{17}$ demonstraram que o sebo foi mais inerte no rúmen que ácidos graxos complexados com cálcio em valores de $\mathrm{pH}$ inferiores a 5,5. Portanto, a dissociação de lipideos no rúmen e seus efeitos sobre a degradabilidade ruminal mantêm estreita relação com os valores de pH ruminal, ou seja, com os outros componentes da dieta e seu nível de consumo.

Como pode ser observado na tabela 4 e figura 3, a degradabilidade ruminal da matéria seca do farelo de soja aumentou linearmente no tempo de 12 horas e na tabela 5 e figura 4 , a degradabilidade ruminal da proteína bruta aumentou linearmente no

Tabela 4 - Efeitos de diferentes níveis de adição de sebo na degradabilidade da MS do farelo de soja, em porcentagens, coeficientes de variação e probabilidades estatísticas. Pirassununga, SP, 1998

\begin{tabular}{|c|c|c|c|c|c|c|c|c|}
\hline MS & \multicolumn{3}{|c|}{ \% de Gordura } & $\mathbf{C V}$ & \multicolumn{2}{|c|}{ Probabilidade } & \multirow[t]{2}{*}{ Equacão $^{1}$} & \multirow[t]{2}{*}{$\underline{\mathbf{R}^{2}}$} \\
\hline$\underline{\text { Tempo(h) }}$ & $\underline{0}$ & $\underline{3}$ & $\underline{6}$ & & $\underline{\mathbf{L}}$ & $\underline{\mathbf{D L}}$ & & \\
\hline$\overline{0}$ & $\overline{----}$ & 16,21 & $\overline{----}$ & $\overline{------}$ & $\overline{---}$ & $\overline{---}$ & $\overline{----}$ & ---- \\
\hline 1,5 & 32,260 & 30,533 & 36,621 & 13,392 & 0,083 & 0,074 & ---- & ---- \\
\hline 3 & 42,198 & 40,303 & 43,280 & 12,441 & 0,722 & 0,366 & --- & --- \\
\hline 6 & 57,926 & 59,043 & 64,375 & 13,570 & 0,166 & 0,581 & --- & --- \\
\hline 12 & 80,765 & 81,226 & 88,810 & 8,296 & 0,042 & 0,252 & $\mathrm{D}=79,578+1,34 \% \mathrm{G}$ & 0,237 \\
\hline 24 & 93,526 & 95,451 & 96,983 & 3,427 & 0,075 & 0,896 & --- & --- \\
\hline 48 & 98,841 & 98,013 & 98,845 & 0,909 & 0,993 & 0,031 & $\mathrm{D}=98,84-0,522 \% \mathrm{G}+$ & 0,201 \\
\hline & & & & & & & $0,092 \% \mathrm{G}^{2}$ & \\
\hline
\end{tabular}

\begin{tabular}{|c|c|c|c|c|c|c|c|c|}
\hline Parâmetros ${ }^{2}$ & & & & & & & & \\
\hline $\mathbf{A}$ & 16,853 & 15,656 & 16,585 & 9,967 & 0,753 & 0,176 & $\begin{array}{l}--- \\
\end{array}$ & $\begin{array}{l}--- \\
\end{array}$ \\
\hline B & 82,115 & 83,813 & 83,311 & 2,819 & 0,402 & 0,375 & --- & --- \\
\hline $\mathbf{C}$ & 0,123 & 0,125 & 0,155 & 25,196 & 0,064 & 0,284 & --- & --- \\
\hline Dp & 98,968 & 99,470 & 99,896 & 1,720 & 0,270 & 0,957 & --- & --- \\
\hline De 0,02 & 87,190 & 87,560 & 89,981 & 2,385 & 0,043 & 0,340 & $\mathrm{D}=86,849+0,465 \% \mathrm{G}$ & 0,310 \\
\hline 0,04 & 78,436 & 78,682 & 82,241 & 3,981 & 0,051 & 0,283 & --- & --- \\
\hline 0,06 & 71,654 & 71,791 & 76,017 & 5,271 & 0,056 & 0,262 & --- & --- \\
\hline
\end{tabular}

${ }^{1} \mathrm{D}=$ degradabilidade, $\% \mathrm{G}=$ porcentagem de sebo, $\mathrm{NS}=$ não significativo.

${ }^{2} a, b$ e $c$ referem-se aos parâmetros de Orskov e McDonald ${ }^{13}, \mathrm{Dp}=$ degradabilidade potencial, $\mathrm{De}=$ degradabilidade efetiva para taxas de passagem iguais a 0,$02 ; 0,04$ e 0,06 .

Números em negrito indicam que houve diferença estatisticamente significativa $(\mathrm{P}<0,05)$ para efeito linear $(\mathrm{L})$ ou desvio da linearidade (DL). 


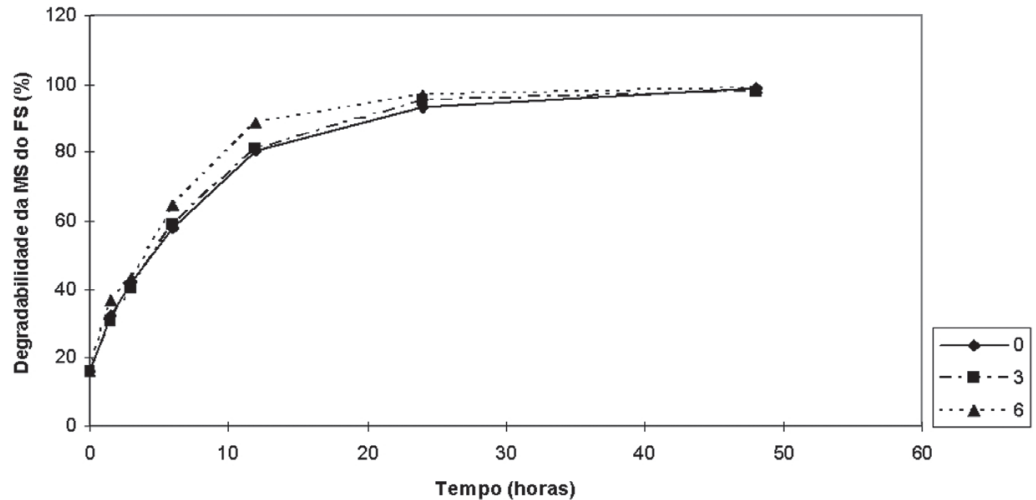

Figura 3 - Efeitos de diferentes níveis de adição de sebo (0, 3, 6\% da MS Total), em diversas horas de incubação,na degradabilidade da MS do farelo de soja

Tabela 5 - Efeitos de diferentes níveis de adição de sebo na degradabilidade da PB do farelo de soja, em porcentagens, coeficientes de variação e probabilidades estatísticas. Pirassununga, SP, 1998

\begin{tabular}{|c|c|c|c|c|c|c|c|c|}
\hline \multirow{2}{*}{$\begin{array}{c}\underline{\text { MS }} \\
\text { Tempo(h) }\end{array}$} & \multicolumn{3}{|c|}{$\%$ de Gordura } & \multirow[t]{2}{*}{$\underline{\mathrm{CV}}$} & \multicolumn{2}{|c|}{ Probabilidade } & \multirow[t]{2}{*}{ Equacão ${ }^{1}$} & \multirow[t]{2}{*}{$\underline{\mathrm{R}^{2}}$} \\
\hline & $\underline{0}$ & $\underline{3}$ & $\underline{6}$ & & $\underline{\mathbf{L}}$ & $\underline{\mathbf{D L}}$ & & \\
\hline $\mathbf{0}$ & ---- & 3,89 & 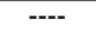 & ------ & --- & --- & $---\cdot$ & ---- \\
\hline \multirow[t]{2}{*}{1,5} & 15,060 & 11,608 & 23,003 & 49,023 & 0,062 & 0,048 & $\mathrm{D}=15,06-3,625 \% \mathrm{G}+$ & 0,365 \\
\hline & & & & & & & $0,824 \% \mathrm{G}^{2}$ & \\
\hline 3 & 28,111 & 25,496 & 30,523 & 30,609 & 0,655 & 0,421 & $----\cdot$ & --- \\
\hline 6 & 48,980 & 47,663 & 55,991 & 23,877 & 0,313 & 0,417 & ---- & --- \\
\hline 12 & 78,436 & 77,661 & 89,953 & 12,795 & 0,062 & 0,193 & ---- & --- \\
\hline 24 & 92,418 & 95,703 & 97,863 & 4,872 & 0,032 & 0,766 & $\mathrm{D}=92,605+0,907 \% \mathrm{G}$ & 0,242 \\
\hline 48 & 99,353 & 98,763 & 99,493 & 0,610 & 0,634 & 0,027 & $\mathrm{D}=99,353-0,416 \% \mathrm{G}+$ & 0,289 \\
\hline & & & & & & & $0,073 \% \mathrm{G}^{2}$ & \\
\hline
\end{tabular}

\begin{tabular}{|c|c|c|c|c|c|c|c|c|}
\hline \multicolumn{9}{|c|}{ Parâmetros $^{2}$} \\
\hline $\bar{A}$ & 1,080 & 0,796 & 1,265 & 514,81 & 0,898 & 0,145 & ----- & ---- \\
\hline $\mathbf{B}$ & 99,478 & 103,01 & 101,06 & 3,803 & 0,506 & 0,202 & ---- & --- \\
\hline $\mathbf{C}$ & 0,115 & 0,112 & 0,148 & 31,617 & 0,132 & 0,266 & ----- & --- \\
\hline Dp & 100,56 & 102,22 & 102,33 & 2,449 & 0,180 & 0,480 & ---- & --- \\
\hline De 0,02 & 86,339 & 85,899 & 89,346 & 3,524 & 0,029 & 0,303 & $\mathrm{D}=84,858+0,667 \% \mathrm{G}$ & 0,302 \\
\hline 0,04 & 74,265 & 74,184 & 79,461 & 6,362 & 0,067 & 0,243 & $-\cdots$ & $-\cdots$ \\
\hline 0,06 & 65,816 & 65,328 & 71,651 & 8,764 & 0,089 & 0,228 & ---. & --- \\
\hline
\end{tabular}

${ }^{1} \mathrm{D}=$ degradabilidade, $\% \mathrm{G}=$ porcentagem de sebo, $\mathrm{NS}=$ não significativo.

${ }^{2} a$, $b$ e $c$ referem-se aos parametros de Orskov e McDonald ${ }^{13}, \mathrm{Dp}=$ degradabilidade potencial, $\mathrm{De}=$ degradabilidade efetiva para taxas de passagem iguais a 0,$02 ; 0,04$ e 0,06 .

Números em negrito indicam que houve diferença estatisticamente significativa $(\mathrm{P}<0,05)$ para efeito linear $(\mathrm{L})$ ou desvio da linearidade (DL). 


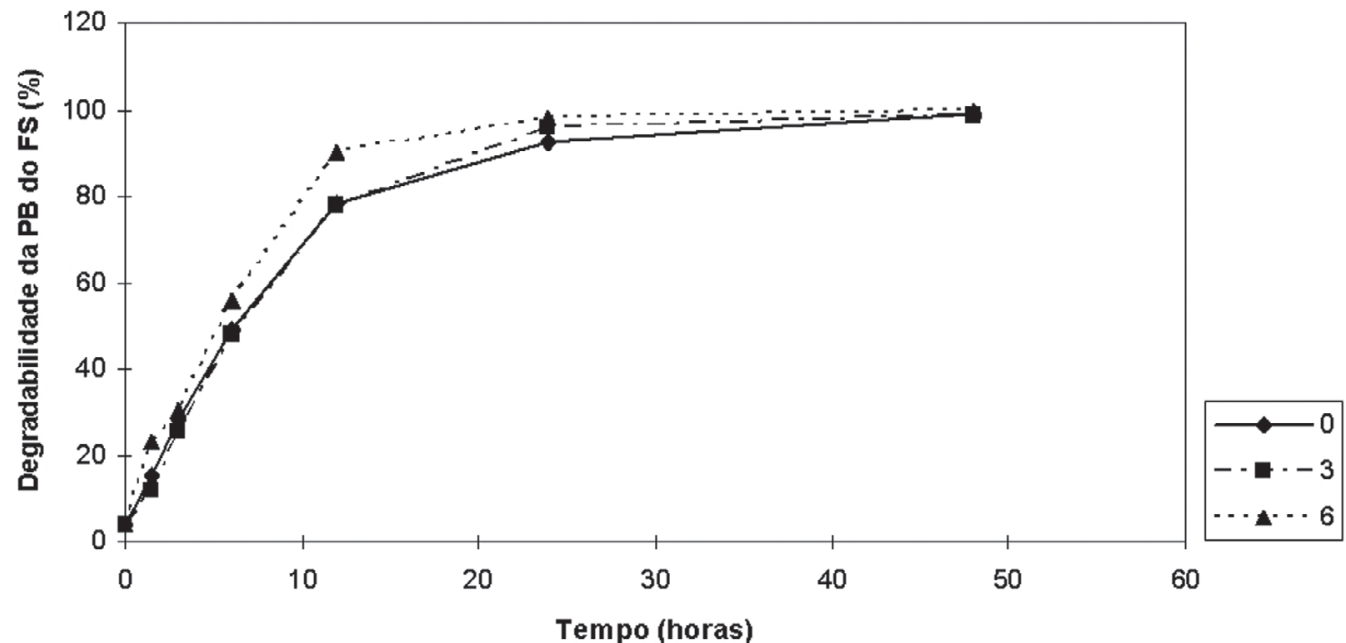

Figura 4 - Efeitos de diferentes níveis de adição de sebo, (0, 3, 6\% da MS Total), em diversas horas de incubação, na degradabilidade da PB do farelo de soja

tempo de 24 horas. O efeito de alteração da microbiota ruminal causado pela dieta com maiores níveis de sebo parece ter beneficiado as bactérias proteolíticas. A possibilidade de ocorrer seleção de microorganismos que degradam a parte protéica do alimento foi comentada por Palmquist ${ }^{5}$, frisando a toxidez dos ácidos graxos principalmente às bactérias celulolíticas, metanogênicas e aos protozoários.

Os protozoários exercem importante papel na degradação de proteínas e vários experimentos mostram o efeito de defaunação dos ácidos graxos de cadeia longa ${ }^{18,24}$. Os trabalhos de Demeyer e Van Nevel ${ }^{28}$ e de Weisbjerg, Borsting e Hvelplund ${ }^{7}$ mostraram a diminuição na degradabilidade da proteína. Porém, os substratos incubados no experimento de Weisbjerg, Borsting e Hvelplund ${ }^{7}$ (forragem e concentrado) foram diferentes deste experimento, sinalizando que as condições de baixo $\mathrm{pH}$ e dietas com menor proporção entre volumosos e concentrados predispõem a esta situação, onde não só as populações de bactérias celulolíticas e protozoários seriam afetadas e não só a degradabilidade da fibra seria prejudicada pela adição de sebo. Como neste experimento o nível de forragem garantiu um $\mathrm{pH}$ ruminal mínimo de 6,3, os ácidos graxos em maior dosagem parecem ter prejudicado marcadamente bactérias celulolíticas e protozoários. Por outro lado, os resultados encontrados por Broudiscou, Van Nevel e Demeyer ${ }^{18}$ não mostram efeitos da adição de gordura na degradação da proteína, ocorrendo tendência em incrementá-la, estando de acordo com os efeitos observados neste trabalho.

Conclui-se que dietas com sebo causaram menor degradabilidade da MS e FDN do feno de Tifton e maior degradabilidade da MS e PB do farelo de soja quando comparada com as dietas sem sebo.

\section{Effects of levels of tallow on in situ degradability of soybean meal and tifton hay \{Cynodon dactylon (L.) Pers.\} in dry cows}

\section{Abstract}

This experiment was carried out to evaluate the effects of tallow supplementation by means of in situ degradability. Three diets, control (without tallow supplementation), diet with $3 \%$ or diet with $6 \%$ of tallow on a dry matter basis, all with $60 \%$ of roughage. The
Key words:

Hay. in situ.

Degradability.

Ruminants.

Soybean meal. Tallow. 
experimental design was a Latin Square $3 \times 3$, using six rumen canulated heifers (480 kg body weight). The experiment had three periods of 28 days, being the first 21 for diet adaptation which was composed of Tifton hay (Cynodon dactylon) and a mixture of concentrate. In situ degradability assay was run from day $21^{\circ}$ to the $28^{\circ}$. Incubation times were $6 ; 12 ; 24 ; 48 ; 72$ and 96 hours for hay dry matter and neutral detergent fiber and 1,5; 3; 6; 12; 24 and 48 hours for soybean meal dry matter and crude protein. The time zero was used to evaluate the soluble fraction. As tallow in the diet increased, there was a decreased in the hay DM and NDF degradabilities and increase in the soybean meal DM and CP degradabilities.

\section{Referências}

1 PALMQUIST, D. L. The role of dietary fats in efficiency of ruminants. Journal of Nutricion, v. 124, p. 1377, 1994. Supplement 8.

2 DAVIS, C. L. Grasas en la Racion. Alimentación De La Vaca Lechera Alta Productora. p. 26-30, 1993.

3 PALMQUIST, D. L.; CONRAD, H. R. Hight fat rations for dairy cows. Tallow and hydrolyzed blended fat at two intakes. Jounal Dairy Science, v. 63, p. 391, 1980.

4 JENKINS, T. C. Lipid metabolism in the rúmen. Journal of Dairy Science, v. 76, n. 12, p. 3851, 1993.

5 PALMQUIST, D. L; BEAULIEU, A. D.; BARBANO, D. M. Feed and animal factors influencing milk fat composition. Jounal Dairy Science, v. 76, p. 1753, 1993.

6 ZINN, R. A. Influence of level and source of dietary fat on its comparative feeding value in finishing diets for steers: Feedlot catlle growth and performance. J. Anim. Sci., v. 67, p. 1029, 1989.

7 WEISBJERG, M. R.; BORSTING C. F.; HVELPLUND, $\mathrm{T}$. The influence of tallow on rúmen metabolism, microbial biomass synthesis and fatty acid composition of bacteria and protozoa. Acta Agric. Scand. Sect. A, Animal Sci., v. 42, p. 106-114, 1992.

8 PIMENTEL GOMES, F. Curso de estatística experimental. Piracicaba: ESALQ, 1985. 467 p.

9 ORSKOV, E. R.; HOVELL, F. D.; MOULD, F. Uso the la tecnica de la bolsa de náilon para la avaluacion de los alimentos. Prod. Animal Trop., v. 5, n.3, p. 213 233,1980

10 CUMMINS, K. A. et al. Nitrogen degradabability and microbial protein synthesis in calves fed diets of varying degradability by the bag technique. Jounal Dairy Science, v. 66, n. 11, p. 2356-2364, 1983.

11 A.O.A.C. Association of Official Analytical Chemists. Official methods of analysis. 10. ed. Washington D.C.: A.O.A.C., 1980.
12 GOERING, H. K.; VAN SOEST, P. J. Forage fiber analysis (Apparatus, reagents, procedures and some applications). Washington D.C.: Agricultural Research Service, 1970. 19 p. (Agriculture handbook, 379).

13 ORSKOV, E. R.; McDONALD, I. The estimation of protein degradability in the rúmen fron incubation measurements weighted according to rate of passage. J. Agric. Sci., v. 92, p. 499-503, 1979

14 SAS. SAS user's guide: statistics. 5. ed. Cary, NC: SAS Inst., 1985.

15 PALMQUIST, D. L.; JENKINS, T. C. Fat in lactation rations: review Jounal Dairy Science, v. 63, n. 1, 1980.

16 EMANUELSON, M.; MURPHY, M.; LINDBERG, J. E. Effects of heat-treated and untreated full-fat rapeseed and tallow on rúmen metabolism, digestibility, milk composition and milk yield in lactating cows. Animal Feed Science and Technology, v. 34, n. 3-4, p. 291309, 1991.

17 SUKHIJA, P. S.; PALMQUIST, D. L. Dissociation of calcium soaps of long-chain fatty acids in rumen fluid. Journal Dairy Science, v. 73, p. 1784, 1990.

18 BROUDISCOU, L.; VAN NEVEL, C. J.; DEMEYER, D. I. Incorporation of soya oil hydrolysate in the diet of defaunated or refaunated sheep: effect on rumen fermentation in vitro. Archiv. Anim. Nutr, v. 40, p. 329, 1990.

19 COPPOC, C.E.; WILKS D. L. Supplemental fat in high -energy rations for lactating cows: effects on intake, digestion, milk yield, and composition. Journal Animal Science, v. 69, p. 3826-3837, 1991.

20 JENKINS, T. C.; JENNY, B. F. Effect of hydrogenated fat on feed intake, nutrient digestion, and lactation performance of dairy cows. Journal Dairy Science, v.72, p. 2316, 1989.

21 JENKINS, T. C.; PALMQUIST, D. L. Effect of fatty acids or calcium soaps on rúmen and total nutrient digestibility of dairy rations. Jounal Dairy Science, v. 67 , p. 978-986, 1984 
22 MACZULACK, A. E.; DEHORITY, B. A.; PALMQUIST, D. L. Effects of long-chain fatty acids on growth of rúmen bacteria. Appl. Environ. Microbiol., v. 42 , p. $856,1981$.

$23 \mathrm{LUCCl}$, C. S. Nutrição e manejo de bovinos leiteiros. São Paulo: Manole, 1997.

24 VAN NEVEL, C. J. Proc. Studiedag: "Vet in vlees en vleesproducten". Gent: Bamst Ed., 1992.

25 CHALUPA, W; FERGUSON, J. D. The Role of Dietary Fat in Productivity and Health of Dairy Cows. The Application of Nutrition in Dairy Practic, p. 3643, 1988.

26 CHALUPA, W. et al. Rumen fermentation in vitro as influenced by long chain fatty acids. Jounal Dairy Science, v. 67, p. 1439-1444, 1984.

27 WEISBJERG, M. R.; BORSTING, C. F. Influence of fat and feed level on fiber digestibility in vitro and in sacco and on volatile fatty acid proportions in tha rúmen. Acta Vet. Scand., v. 86, p. 137-139, 1989. Supplement.

28 DEMEYER, D. I.; VAN NEVEL, C. J. Transformations and effects of lipids in the rúmen: Three decades of research at gent university. Arch. Anim. Nutr., v. 48, p. 119-134, 1995. 